\title{
Fluorophotometric Measurements of Tear Turnover Rate in Normal Healthy Persons: Evidence for a Circadian Rhythm
}

\author{
W. R. S. WEBBER, D. P. JONES and P. WRIGHT* \\ London
}

\begin{abstract}
Summary
The determination of tear turnover rate in a total of 16 normal healthy volunteers is described. A continuous reading fluorophotometer is used to measure the fluorescence resulting from the instillation of $1 \mu \mathrm{l}$ of 2 per cent fluorescein into the eye. A mean ( \pm s.d.) turnover rate of $14.9 \pm 5.6$ per cent per minute is found, in agreement with previously reported values. Morning and afternoon measurements on the same subject show that morning tear turnover rates are significantly higher than those in the afternoon $(\mathrm{p}<0.01)$, suggesting a circadian rhythm in tearflow. It is also concluded that use of a 10 per cent fluorescein solution can lead to a significant underestimation of tear turnover rates and that any resulting errors are likely to be larger for light coloured irises.
\end{abstract}

Disorders of the tear secretory system are commonly encountered in ophthalmic practice, but it is rarely possible to establish a direct association between the symptoms and the tear flow because of the difficulty of making accurate tear flow measurements. Clinical clues such as a papillary reaction in the conjunctiva, particulate matter in the tear film, filamentary keratopathy, corneal or conjunctival staining with fluorescein and Rose Bengal, may all suggest disordered tear flow, but are not diagnostic and do not quantify tear production. Schirmer's test, with or without anaesthetic, is the classical filter paper test for dry eyes, but the measurements have been shown to have very poor reproducibility and huge standard deviations even in normal subjects. ${ }^{1.2}$ Modification of the test involving movement of the strip after 2 minutes has been suggested to eliminate false positive tests, but even the modified test is unreliable for detecting moderately depleted tear secretion. ${ }^{3}$ Colorimetric methods using dyes are more satisfactory but they cannot follow rapid changes in tear flow and are often subjective. ${ }^{4}$ Fluorophotometric methods $s^{5,6.7 .8}$ have several advantages for tear turnover measurements. They are objective, they require the instillation of only a very small quantity of fluorescein, and the continuous reading types of fluorophotometer can follow dynamic tear flow changes. ${ }^{5.6 .7}$

The continuous reading fluorophotometer previously described ${ }^{6.7}$ was used to make tear turnover measurements in normal healthy volunteers for periods of up to 30 minutes. Basal tear turnover rate is very variable v.10 $^{9.10}$ since environmental stimuli, psychological factors, and even the effort of keeping the eyes open ${ }^{11}$ can influence the results. It has also been found that variations in the blink rate in some individuals can lead to quite dra-

Department of Medical Electronics, St Bartholomew's Hospital, London EC1A 7BE and *Moorfield's Eye Hospital, City Road, London EC1V 2PD.

Correspondence to: Dr. D. P. Jones, Department of Medical Electronics, St. Bartholomew's Hospital, London EC1A 7BE. 
matic changes in tear turnover, suggesting that blink rate is a factor that should be controlled in any tear turnover measurement. ${ }^{12}$ In an earlier preliminary investigation single determinations of the tear turnover rate were made in different normal individuals who were randomly allocated to either morning or afternoon sessions. ${ }^{13}$ The results provided some evidence of a difference between the morning and afternoon tear turnover rates. A more detailed study of this phenomenon is described below in which normal healthy volunteers were measured both in the morning and in the afternoon so that the two turnover rates for each subject could be compared directly.

In our tear turnover determinations a 2 per cent fluorescein solution is usually instilled, but there have been reports of higher concentrations being used. There is experimental evidence $^{12}$ that high concentrations of fluorescein can lead to errors due to the possibility of dye extinction. ${ }^{14}$ Thus, the effect of increasing the concentration of fluorescein on the measured tear turnover has been investigated and the results of this study are also presented.

\section{Material and Methods}

Measurements were made on a total of 16 normal healthy volunteers (6 Female, 10 Male) with no history of eye disease whose ages ranged from 21 to 39 years with an average age of $27.6 \pm 5$ years (mean \pm s.d.). Green, grey and blue irises were designated light (L) and brown irises dark (D) using the eye colour coding system of Coakes and Brubaker. ${ }^{15}$

All measurements were made at a temperature of $20 \pm 1$ degree $\mathrm{C}$ in a basement darkroom where conditions were relatively stable. Each tear turnover measurement began by the instillation of 2 per cent fluorescein $(20 \mathrm{mg} / \mathrm{ml})$ into the eye. A syringe needle ( $1 \mu$ l capacity) with a $1 \mu \mathrm{l}$ drop of fluorescein at its tip was lightly touched tangentially on the superior bulbar conjunctiva of the eye. A small drop was used so as to cause minimal interference with the tear film. The subject was then requested to blink three times to distribute the dye throughout the film.

Tear flow measurements were made using an improved version of our continuous reading fluorophotometer. ${ }^{6.7}$ This instrument has a measurement volume of $0.6 \times 0.2 \times 0.4 \mathrm{~mm}$ formed by the intersection of the slit-lamp beam and the projec- tion of the collecting aperture of the photometric microscope used to detect fluorescence; the angle between the illumination and collection axes is 70 degrees. The output of the instrument is proportional to the fluorescence within the measurement volume. The subject views a red-green light emitting diode with the eye which is not being measured and this is used both as a fixation light and as a blink rate controller. The subject is requested to blink in time with an easily followed colour change signal. ${ }^{12}$

Tear fluorescence was measured continuously for 3 to 4 minutes with the fluorophotometer output displayed on a chart recorder. During the measurement procedure the blink rate was regulated to once every 8 seconds ( 7.5 per $\min$ ) by the blink/ fixation light. This rate gave a length of trace between blink artefacts which was sufficient to make interpretation of the records relatively easy yet was high enough to be comfortable for the subject. A two minute rest period was taken and the procedure repeated. In practice, both eyes were usually measured on the same occasion in which case each eye was measured in turn with a rest period after every other measurement. This procedure yielded a sequence of interleaved left and right eye results and was continued for up to 30 minutes after dye instillation or until the tear film fluorescence was too small to measure if this occurred earlier. The time limit was set to avoid errors due to corneal fluorescence; fluorescein slowly diffuses into the cornea where it accumulates and eventually makes a significant, but unwanted, contribution to the measured tear fluorescence. 12

The results were analysed using the equation: $C_{d}$ $=C_{d o} \exp \left(-Q_{d} t\right)$, where $C_{d}$ is the tear film concentration, $C_{d o}$ is the value of $C_{d}$ immediately after instillation of dye and $Q_{d}$ and $t$ are the turnover rate and the time from the instillation of the dye, respectively. ${ }^{7}$ The turnover rate $Q_{d}$ and the standard deviation for each eye were calculated using linear regression on the plot of the natural logarithm of the instrument output readings (i.e. relative concentration) against time for points selected from the beginning and end of each of the two to three minute long measurement intervals.

Tear turnover rates for 11 subjects $(9 \mathrm{M}, 2 \mathrm{~F})$ were determined using a low concentration ( 2 per cent) of fluorescein. Nine of these subjects were measured both in the morning before 13:00 hours and in the afternoon so that the morning and afternoon tear flows in the same subject could be compared. The two measurements were made on different days to ensure that the second measurement was not influenced by the proximity of the first. Since there was a possibility that the subject might be apprehensive on the first occasion and that this could influence the results, five subjects were 
measured in the morning first and the other four were measured first in the afternoon.

The effect of instilling a higher dye concentration was studied by making tear turnover measurements in the morning only on 10 subjects using 10 per cent fluorescein $(100 \mathrm{mg} / \mathrm{ml})$. Five of these had already been measured using 2 per cent fluorescein while the other five $(2 \mathrm{M}, 3 \mathrm{~F})$ had not been measured before.

The tear turnover data appeared to be approximately normally distributed and two-sample and paired t-tests were used as appropriate for comparing results. The Mann-Whitney U-test was used for samples whose variances differed significantly. In all cases the significance criterion was set at the 5 per cent level.

\section{Results}

The tear turnover results when 2 per cent fluorescein was used are shown in Table I. The measurements for each subject were performed in the order in which they are entered e.g. for subject 4 the right eye (R) was measured in the morning (A) first and the left and right eyes were both measured together in the afternoon $(\mathrm{P})$. An entry in Table I showing that the left and right eyes were both measured in the morning or the afternoon implies interleaved measurements on the same occasion except for subjects 1 and 3 where each determination was made on a dif-

Table I. Tear turnover results for 2 per cent fluorescein. The measurements on each subject were performed in the order of entry. When right $(R)$ and left $(L)$ eyes are both shown as measured in the afternoon $(P)$ or in the morning $(A)$ they were measured on the same occasion except for subjects 1 and 3 where each measurement was performed on a different day. The iris type is light $(L)$ or dark $(D)$

\begin{tabular}{|c|c|c|c|c|c|}
\hline $\begin{array}{l}\text { Subject } \\
\text { No. }\end{array}$ & Sex & Eye & Time & $\begin{array}{l}\text { Iris } \\
\text { type }\end{array}$ & $\begin{array}{l}\text { Turnover } \pm S . D . \\
\text { per cent per min }\end{array}$ \\
\hline \multirow[t]{2}{*}{1} & $\mathrm{M}$ & $\mathrm{L}$ & A & D & $15.2 \pm 1.1$ \\
\hline & & $\mathrm{R}$ & A & D & $13.6 \pm 2.0$ \\
\hline \multirow[t]{2}{*}{2} & $\mathrm{~F}$ & $\mathrm{~L}$ & A & $\mathrm{L}$ & $7.8 \pm 0.8$ \\
\hline & & $\mathrm{R}$ & A & $\mathrm{L}$ & $5.8 \pm 0.8$ \\
\hline \multirow[t]{3}{*}{3} & $\mathrm{M}$ & $\mathrm{L}$ & $\mathrm{P}$ & $\mathrm{L}$ & $9.8 \pm 0.5$ \\
\hline & & $\mathrm{L}$ & A & $\mathrm{L}$ & $20.0 \pm 2.2$ \\
\hline & & $\mathrm{R}$ & A & $\mathrm{L}$ & $23.0 \pm 1.3$ \\
\hline \multirow[t]{3}{*}{4} & M & $\mathrm{R}$ & A & $\mathrm{L}$ & $18.7 \pm 1.3$ \\
\hline & & $\mathrm{L}$ & $P$ & $\mathrm{~L}$ & $16.4 \pm 1.2$ \\
\hline & & $\mathrm{R}$ & $P$ & $\mathrm{~L}$ & $15.4 \pm 1.2$ \\
\hline \multirow[t]{3}{*}{5} & $\mathrm{M}$ & $\mathrm{L}$ & A & $\mathrm{L}$ & $12.7 \pm 1.8$ \\
\hline & & $\mathrm{L}$ & $\mathrm{P}$ & $\mathrm{L}$ & $5.8 \pm 0.9$ \\
\hline & & $\mathrm{R}$ & $\mathrm{P}$ & $\mathrm{L}$ & $5.2 \pm 0.7$ \\
\hline \multirow[t]{3}{*}{6} & M & $\mathrm{R}$ & $\mathrm{P}$ & D & $5.8 \pm 2.0$ \\
\hline & & $\mathrm{L}$ & A & $\mathrm{D}$ & $12.4 \pm 3.8$ \\
\hline & & $\mathrm{R}$ & A & $\mathrm{D}$ & $20.4 \pm 4.8$ \\
\hline \multirow[t]{4}{*}{7} & M & $\mathrm{L}$ & A & $\mathrm{L}$ & $20.0 \pm 4.0$ \\
\hline & & $\mathrm{R}$ & A & $\mathrm{L}$ & $15.7 \pm 2.1$ \\
\hline & & $\mathrm{L}$ & $P$ & $\mathrm{~L}$ & $19.0 \pm 4.0$ \\
\hline & & $\mathrm{R}$ & $\mathrm{P}$ & $\mathrm{L}$ & $15.3 \pm 3.0$ \\
\hline \multirow[t]{4}{*}{8} & $F$ & $\mathrm{~L}$ & $\mathrm{P}$ & D & $18.1 \pm 3.0$ \\
\hline & & $\mathrm{R}$ & $\mathrm{P}$ & D & $16.1 \pm 0.1$ \\
\hline & & $\mathrm{L}$ & A & D & $18.0 \pm 1.6$ \\
\hline & & $\mathrm{R}$ & A & D & $22.6 \pm 1.6$ \\
\hline \multirow[t]{4}{*}{9} & M & $\mathrm{L}$ & A & D & $17.5 \pm 3.0$ \\
\hline & & $\mathrm{R}$ & A & D & $7.5 \pm 2.2$ \\
\hline & & $\mathrm{L}$ & $P$ & D & $11.6 \pm 1.6$ \\
\hline & & $\mathrm{R}$ & $P$ & D & $15.7 \pm 1.5$ \\
\hline \multirow[t]{4}{*}{10} & $M$ & $\mathrm{~L}$ & $P$ & $\mathrm{~L}$ & $15.5 \pm 1.5$ \\
\hline & & $\mathrm{R}$ & $\mathrm{P}$ & $\mathrm{L}$ & $13.6 \pm 0.5$ \\
\hline & & $\mathrm{L}$ & A & $\mathrm{L}$ & $27.2 \pm 3.6$ \\
\hline & & $\mathrm{R}$ & A & $\mathrm{L}$ & $26.4 \pm 2.6$ \\
\hline \multirow[t]{4}{*}{11} & M & $\mathrm{L}$ & A & $\mathrm{L}$ & $13.2 \pm 0.2$ \\
\hline & & $\mathrm{R}$ & A & $\mathrm{L}$ & $13.6 \pm 0.9$ \\
\hline & & $\mathrm{L}$ & $\mathrm{P}$ & $\mathrm{L}$ & $9.9 \pm 0.5$ \\
\hline & & $\mathrm{R}$ & $\mathrm{P}$ & $\mathrm{L}$ & $11.4 \pm 1.6$ \\
\hline
\end{tabular}


Table II. Summary of results of paired t-tests on the data of Table I

\begin{tabular}{lccc}
\hline & LEFT : RIGHT & $1 S T: 2 N D$ & $A M: P M$ \\
\hline SUBJECTS & 9 & 9 & 9 \\
EYES & 18 & 14 & 14 \\
df & 8 & 13 & 13 \\
$\mathrm{p}$ & $>0.35 \mathrm{~N} . \mathrm{S}$ & $>0.15 \mathrm{~N} . \mathrm{S}$. & $<0.01$ \\
\hline
\end{tabular}

Table III. Tear turnover results for left $(L)$ and right $(R)$ eyes and light $(L)$ and dark $(D)$ iris types using 10 per cent fluorescein. All measurements made in the morning.

\begin{tabular}{|c|c|c|c|c|}
\hline $\begin{array}{l}\text { Subject } \\
\text { No. }\end{array}$ & Sex & Eye & $\begin{array}{l}\text { Iris } \\
\text { type }\end{array}$ & $\begin{array}{l}\text { Turnover } \pm S . D . \\
\text { per cent per min }\end{array}$ \\
\hline \multirow[t]{2}{*}{1} & $M$ & $\mathrm{~L}$ & $\mathrm{D}$ & $6.5 \pm 0.9$ \\
\hline & & $\mathrm{R}$ & D & $5.0 \pm 0.8$ \\
\hline \multirow[t]{2}{*}{3} & $\mathrm{M}$ & $\mathrm{L}$ & $\mathrm{L}$ & $8.5 \pm 1.5$ \\
\hline & & $\mathrm{R}$ & $\mathrm{L}$ & $10.5 \pm 1.5$ \\
\hline \multirow[t]{2}{*}{4} & $\mathrm{M}$ & $\mathrm{L}$ & $\mathrm{L}$ & $10.9 \pm 0.8$ \\
\hline & & $\mathrm{R}$ & $\mathrm{L}$ & $8.6 \pm 1.4$ \\
\hline \multirow[t]{2}{*}{8} & $\mathrm{~F}$ & $\mathrm{~L}$ & D & $19.5 \pm 1.3$ \\
\hline & & $\mathrm{R}$ & D & $21.5 \pm 2.6$ \\
\hline \multirow[t]{2}{*}{11} & M & $\mathrm{L}$ & $\mathrm{L}$ & $6.0 \pm 0.8$ \\
\hline & & $\mathrm{R}$ & $\mathrm{L}$ & $7.1 \pm 1.3$ \\
\hline \multirow[t]{2}{*}{12} & M & $\mathrm{L}$ & $\mathrm{L}$ & $6.8 \pm 0.6$ \\
\hline & & $\mathrm{R}$ & $\mathrm{L}$ & $7.0 \pm 1.1$ \\
\hline \multirow[t]{2}{*}{13} & M & $\mathrm{L}$ & D & $15.2 \pm 0.6$ \\
\hline & & $\mathrm{R}$ & D & $15.2 \pm 1.6$ \\
\hline \multirow[t]{2}{*}{14} & $\mathrm{~F}$ & $\mathrm{~L}$ & D & $7.4 \pm 0.7$ \\
\hline & & $\mathrm{R}$ & D & $10.0 \pm 1.6$ \\
\hline \multirow[t]{2}{*}{15} & $\mathrm{~F}$ & $\mathrm{~L}$ & D & $14.1 \pm 2.7$ \\
\hline & & $\mathrm{R}$ & D & $19.8 \pm 2.4$ \\
\hline \multirow[t]{2}{*}{16} & $\mathrm{~F}$ & $\mathrm{~L}$ & $\mathrm{~L}$ & $12.6 \pm 0.9$ \\
\hline & & $\mathrm{R}$ & $\mathrm{L}$ & $8.8 \pm 1.4$ \\
\hline
\end{tabular}

ferent day. The tear turnover rates in Table I range from 5.2 to 27.2 per cent per minute with a mean value ( \pm s.d.) of $14.9 \pm 5.6$ per cent per minute and are in agreement with previously published data..$^{8.12}$

No significant difference could be found using a paired t-test between right and left eye readings made on the same occasion, as shown in Table II. This result was unchanged if the repeated readings for subjects 7 to 11 were also included. First readings were compared with second readings on the same eye, irrespective of when the measurements were done, by means of a paired t-test. No significant difference was found, indicating that the order in which the measurements were performed did not influence the result, see Table II.

Nine subjects ( 3 to 11 in Table I) had at least one eye measured both in the morning (A) and in the afternoon $(\mathrm{P})$.
The morning tear turnover rates were found to be significantly higher than those for the afternoon, again using a paired t-test, see Table II; the mean values ( \pm s.d.) for the two groups were $18.1 \pm 5.4$ and $13.1 \pm 4.2$ per cent per minute, respectively.

There was no significant difference between the 2 per cent fluorescein results for light and dark irises using a two-sample t-test. Morning and afternoon data were compared separately to avoid interference from the time of day effect found above.

Table III shows the tear turnover results obtained for 10 per cent fluorescein in 10 subjects, all of whom were measured in the morning. The mean turnover rate $( \pm$ s.d.) is 11.0 \pm 5.0 per cent per minute. Again, no significant difference could be found between the tear turnover values for left and right eyes using a paired t-test, nor between the results for light (L) and (D) irises using a MannWhitney U-test. 
Table IV. Results of two-sample tests to compare tear turnover when using 2 per cent and 10 per cent fluorescein. All measurements made in the morning.

\begin{tabular}{lcccl}
\hline $\begin{array}{l}\text { Iris } \\
\text { type } \\
\text { L/D }\end{array}$ & $\begin{array}{c}\text { Dye } \\
\text { conc. } \\
\text { per cent }\end{array}$ & $\begin{array}{c}\text { No. of } \\
\text { eyes } \\
n\end{array}$ & $\begin{array}{c}\text { Mean }( \pm S . D .) \\
\text { turnover rate } \\
\text { per cent per min }\end{array}$ & \multicolumn{1}{c}{ Statistic } \\
\hline Both & 2 & 20 & $16.6 \pm 5.9$ & $\mathrm{t}=3.19 \mathrm{df}=38$ \\
Both & 10 & 20 & $11.0 \pm 5.0$ & $\mathrm{p}<0.005$ \\
L & 2 & 12 & $17.0 \pm 6.8$ & $\mathrm{U}=16$ \\
L & 10 & 10 & $8.7 \pm 2.1$ & $\mathrm{p}<0.02$ \\
D & 2 & 8 & $15.9 \pm 4.8$ & $\mathrm{t}=0.96 \mathrm{df}=16$ \\
D & 10 & 10 & $13.4 \pm 5.9$ & $\mathrm{~N} . \mathrm{S} .(\mathrm{p}>0.35)$ \\
\hline
\end{tabular}

The tear turnover results for 2 per cent and 10 per cent fluorescein in Tables I and III were compared by means of a paired t-test for the five subjects who had received both dye concentrations (i.e. the first five subjects in Table III). To avoid any time of day effect only the morning readings from Table I were used. It was found that the 2 per cent turnover readings were significantly higher than the 10 per cent values $(p<0.01)$, the mean difference $( \pm$ s.d.) being $7.2 \pm 4.7$ per cent per minute.

The results for all subjects in Table III were also compared with the morning only readings for all 11 subjects in Table I by means of a twosample t-test. This again showed that the 2 per cent fluorescein readings were significantly higher than those for 10 per cent fluorescein, as shown in Table IV. When only the light iris (L) results were considered, the 2 per cent fluorescein values were also significantly higher than the 10 per cent fluorescein values using a Mann-Whitney U-test. However, for subjects with dark irises, although there was a similar trend towards higher turnover rates at the lower dye concentration, there was no significant difference between the 2 per cent and 10 per cent results in this case. (see Table IV).

\section{Discussion and Conclusions}

The present results show that tear turnover rates are significantly higher in the morning than they are in the afternoon and support the earlier suggestion ${ }^{13}$ that there may be a circadian rhythm in tear flow. There appears to be only one other investigation of long term fluctuations in tear flow, that of Henderson and Prough. ${ }^{16}$ These authors could find no dependence of tear flow on time of day, probably because they used Schirmer's method which, as already pointed out, is prone to large errors. Tear production can be strongly influenced by the central nervous system and the changes that have been found may be similar to the periodic variations which have been identified in aqueous flow, ${ }^{17}$ pupillary activity ${ }^{18}$ and gastric motility. ${ }^{19}$ Further work is needed both to establish the details of the tear flow pattern and to see whether it is also present in patients with disorders of tear secretion.

The tear turnover rates measured using 10 per cent fluorescein were significantly lower than those recorded with the 2 per cent dye solution. This trend was also found when the light and dark iris results were considered separately, although it only reached statistical significance for light irises. There is both theoretical and experimental evidence that a $1 \mu \mathrm{l}$ drop of 10 per cent fluorescein solution can induce marked dye extinction and absorption effects in the tear film, particularly near the time of instillation. ${ }^{12}$ These phenomena cause the fluorescence and its rate of decay to be underestimated and probably account for the lower turnover rates observed here. The near zero tear flow rates reported for some subjects by other investigators who used a 10 per cent solution $^{8}$ may also be due to these effects.

The reduction in mean tear turnover rate with the 10 per cent fluorescein solution tends to be greater for light irises than for dark irises (see Table IV). This difference may be due to preferential scattering of the blue excitation radiation by light irises. Shortly after instillation the high dye concentration in the tear film partially shields the iris from the excitation light. Later, as the concentration falls, sufficient light may be back scattered into the measurement volume by a light iris to signifi- 
cantly enhance the recorded fluorescence and give an apparent decrease in the tear turnover rate. In contrast, for 2 per cent fluorescein the initial attenuation by the stained tear film is much less and should be linearly related to dye concentration. ${ }^{12}$ Hence, throughout a 2 per cent fluorescein measurement the scattered light from both iris types should vary approximately linearly with concentration, resulting in a measured turnover rate independent of the iris type. It is concluded that a $1 \mu$ drop of 10 per cent fluorescein solution introduces too large a quantity of dye into the tear film to ensure accurate tear turnover measurements and that any resulting errors may be worse for subjects with light irises.

In summary, it has been shown that morning tear turnover rates are higher than those in the afternoon, suggesting a circadian rhythm in tear flow. In addition, these results confirm that the use of a 10 per cent fluorescein solution in the fluorophotometric method can lead to a significant underestimation of the tear turnover rate and that such relatively high concentrations should be avoided.

The authors thank Dr. E. D. Cooke and Sally Bowcock S.R.N. for instilling the fluorescein dye. WRSW acknowledges the financial support of the Medical Research Council.

\section{References}

I Pinschmidt NW: Evaluation of the Schirmer tear test. South Med J 1970, 63: 1256.

2 Shapiro A and Merin S: Schirmer test and break up time of tear film in normal subjects. $A m J$ Ophthalmol 1979, 88: 752-7.

${ }^{3}$ Mackie IA and Seal DV: The questionably dry eye. Br J Ophthalmol 1981, 65: 2-9.

${ }^{4}$ Norn MS: Tear secretion in normal eyes. Acta Ophthalmol 1965, 43: 567-73.
5 Furukawa RE, Polse KA, Emori Y: Slit-lamp fluorophotometry. Opt Eng 1976, 15: 321-4.

${ }^{6}$ Smith AT, Jones DP, Sturrock GD, Wright P: An improved objective slit-lamp fluorophotometer using tungsten-halogen lamp excitation and synchronous detection. Br J Ophthalmol 1977, 61: 722-5.

7 Jones DP, Smith AT, Sturrock GD, Wright P: Ophthalmic fluorophotometry: An improved slit-lamp fluorophotometer. Med Biol Eng Comput 1979, 17: 365-70.

${ }^{8}$ Puffer MJ, Neault RW, Brubaker RF: Basal precorneal tear turnover in the human eye. $A m J$ Ophthalmol 1980, 89: 369-76.

${ }^{9}$ Mishima S, Gasset A, Klyce Jr SD, Baum JL: Determination of tear volume and flow. Invest Ophthalmol 1966 5: 264-75.

1" Jordan A and Baum JL: Basic tear flow-does it exist? Ophthalmol 1980, 87: 920-30.

${ }^{11}$ De Roeth A: Lacrimation in normal eyes. Arch Ophthalmol 1953, 49: 185-9.

12 Webber WRS and Jones DP: Continuous fluorophotometric method of measuring tear turnover rate in humans and analysis of factors affecting accuracy. Med Biol Eng Comput 1986. 24: $386-92$.

1.3 Webber WRS, Jones DP, Wright P: Measurements of tear turnover in normal healthy persons by fluorophotometry suggest a circadian rhythm. IRCS Med Sci 1984, 12: 683-4.

${ }^{14}$ Maurice DM: The use of fluorescein in ophthalmological research. Invest Ophthalmol 1967, 6: 464 77.

15 Coakes RL and Brubaker RF: Method of measuring aqueous humour flow and corneal endothelial permeability using a fluorophotometry nomogram. Invest Ophthalmol Vis Sci 1979, 18: 288302 .

${ }^{16}$ Henderson JW and Prough WA: Influence of age and sex on flow of tears. Arch Ophthalmol 1950. 43: $224-31$.

${ }^{17}$ Ericson LA: Twenty four hour variations of the aqueous flow (examination with perilimbal suction cups). Acta Ophthalmol [Suppl 50] (Copenh) 1958.

${ }^{18}$ Lavie P: Ultradian rhythms in alertness-a pupillometric study. Biol Psychol 1979, 9: 49-62.

${ }^{19}$ Hiatt JF and Kripke DF: Ultradian rhythms in waking gastric activity. Psychosom Med 1985, 37: $320-5$. 